\title{
ADVANCES IN PAIN MANAGEMENT FOR VETERANS: CURRENT STATUS OF RESEARCH AND FUTURE DIRECTIONS
}

Robert D. Kerns, PhD; Alicia A. Heapy, PhD

$\mathrm{M}$ ilitary Veterans have been identified as being particularly vulnerable to the development and perpetuation of pain [1]. Among the 23 million U.S. military Veterans, it has been estimated that as many as $\mathbf{5 0}$ percent of male Veterans and as many as 75 percent of female Veterans experience chronic pain [2]. Painful musculoskeletal conditions are the most common disorders among Veterans returning from the recent conflicts in Iraq and Afghanistan, surpassing the rates of all mental health conditions combined [3]. Pain among these Veterans is highly comorbid with the "signature injuries" of these conflicts, namely posttraumatic stress disorder (PTSD) and traumatic brain injury [4]. Although not unique to Veterans, compounding the challenges associated with successful management of chronic pain is continued evidence of a provider workforce that is ill-prepared to assess and manage common pain conditions [5], limited effectiveness of analgesic medications and other nonpharmacological approaches [6], and growing concerns about harms associated with long-term opioid therapy [7]. In 2011, the Institute of Medicine (IOM) published its seminal report, "Relieving pain in America: A blueprint for transforming prevention, care, education, and research," and called on the Department of Veterans Affairs (VA) and other Government and stakeholder groups to renew their commitment to this national transformational effort [1].

Research on pain among Veterans is not new. In fact, some of the early pioneering work to advance the multidimensional assessment of chronic pain and establish the efficacy of psychological approaches for pain management was conducted in the VA [8-9]. By 1998, former VA Undersecretary for Health Kenneth Kizer, MD, identified the need for more pain research as one of the objectives of a VA Pain Management Strategy [10]. A special topic issue of the Journal of Rehabilitation Research and Development (JRRD) in 2007 highlighted sustained growth in the VA pain research portfo- lio [11], and annual reports since that time provide evidence of yearly growth in terms of the number, scope, and financial expenditures in support of the VA's pain research portfolio.

This special topic issue of $J R R D$ presents results from pain research projects taking place in the VA healthcare system, with a focus on innovative research and its practice and policy implications. The specific objectives of the issue are to educate readers about (1) special issues faced by Veterans with pain, especially Veterans of the recent wars in Iraq and Afghanistan; (2) potential sources of inequities in pain care that may have special relevance for Veterans; and (3) novel approaches to the assessment and treatment of pain and comorbid conditions for Veterans with pain. As such, contributions to this special issue come from the VA clinical, rehabilitation, and health services research communities as opposed to investigators conducting basic laboratory science and preclinical research. Ultimately, we hope that the series of original articles that comprise this special issue will convey a sense of the robust pain-relevant research program in the VA and inform an agenda for further research addressing the management of pain in Veterans and other groups.

Contributions to this special topic issue offer a window into the exciting, innovative, and important pain-relevant research being conducted in the VA that directly informs the VA's efforts to address the challenge of the IOM. As just one example, a key finding of the IOM was the lack of consistent data that document the incidence and prevalence of pain and its effects on activities 
of daily living and work, use of healthcare and social services, and costs of pain and pain care and the recommendation to "improve the collection and reporting of data on pain" [1]. The VA is ideally positioned to address this recommendation because it has one of the most comprehensive electronic health record (EHR) systems in the United States, which includes longitudinal clinical assessments (e.g., pain intensity screening), treatments, and outcomes data. These clinical data are complemented by a comprehensive registry of administrative and descriptive data for Veterans in VA care. Given this important strength of research conducted using VA data, it is gratifying that a number of articles in this special topic issue report on analyses of VA administrative and clinical data to address gaps in the epidemiology of pain and pain care and inform quality and performance improvement initiatives and additional research.

The special issue begins with a contribution by Erica A. Abel, PhD, et al. that shares results of a survey of VA clinical and health services investigators regarding the perceived use of VA data for observational research and opens the discussion on the use of these data to define key constructs such as "chronic pain" and "long-term opioid therapy." This foundational article is followed by several that used observational methods to examine key questions using VA's electronic data. One of the earliest VA investigators to use VA data to examine pain care in VA is Diana J. Burgess, PhD. In this special topic issue, Burgess et al. use the VA's Survey of Healthcare Experiences of Patients (SHEP) data matched with EHR data from the selected sample of Veterans who participated in the SHEP to examine whether pain outcomes (pain interference, perceived pain treatment effectiveness) vary by race and then whether opioid use moderates these associations. Three articles used similar methods to examine pain and important comorbidities. Travis I. Lovejoy, PhD, MPH, et al. examined Veterans with comorbid pain and substance use disorders and predictors of receipt of opioid therapy, usually contraindicated for this population due to the risk of prescription opioid addiction, exacerbation of other substance use disorders, and other harms. Samantha D. Outcalt, PhD, et al. used clinical and administrative data to examine whether pain moderates receipt of guideline-concordant treatment for Veterans with PTSD. Unfortunately, Veterans who had a positive screen for PTSD and documented chronic pain were less likely to receive mental health care relative to those without comorbid chronic pain. April F. Mohanty, MPH, PhD, et al. from the War
Related IIIness and Injury Study Center (WRIISC), which emphasizes research on Veterans from recent conflicts in the Middle East, used longitudinal VA data to examine comorbidities and the course of care for Veterans with fibromyalgia syndrome. The methods employed in these studies can serve as important models for future research using VA's EHR system and other databases to address the IOM's charge for high-quality epidemiological research that examines pain and pain care.

This series of studies is complemented by two articles that employed survey methods to examine pain and important comorbidities. Lisa M. McAndrew, PhD, also from WRIISC, and her colleagues report on findings that significantly extend our understanding of pain in the context of a larger condition of diffuse chronic multisymptom illness (CMI). They used data from a longitudinal study of Veterans from the recent wars in Iraq and Afghanistan to document that a majority of Veterans from this era reported the presence of symptoms consistent with $\mathrm{CMI}$ and that approximately 90 percent of Veterans reporting pain met the criteria for CMI. Further, CMI was associated with significantly worse physical health functioning that was not accounted for by concurrent PTSD. Diana M. Higgins, PhD, et al. examined data from the MOVE!23 survey that is routinely collected from Veterans participating in MOVE!, VA's weight-management program. Among those completing the survey, 72 percent reported painful conditions. Particularly provocative was the observation that pain was associated with multiple other medical and mental health comorbidities. Together, these studies all argue for consideration of pain as a surrogate or marker for poor health, generally speaking, and strongly reinforce emerging observations that pain may be an important moderator and/or mediator of other health conditions and their treatment and outcomes of treatment.

Shifting from studies using observational data, three articles report on secondary analyses of data collected in the context of treatment for chronic pain. In the first of these reports, Jennifer L. Murphy, PhD, et al. from the VA's award-winning Chronic Pain Rehabilitation Program at the James A. Haley Veterans' Hospital examined the influence of sex as a moderator of treatment outcome and maintenance of its effects. Most striking was the observation that female Veterans were less likely than male Veterans to maintain improvements in pain intensity and sleep quality at a 3 mo follow-up evaluation following completion of the $3 \mathrm{wk}$ residential program. Treatments that promote healthy 
lifestyles, including exercise, walking, and structured activity, have begun to be documented as important strategies for reducing pain and improving functioning among those with chronic pain. In a highly innovative and exciting line of research, Erica Scioli-Salter, $\mathrm{PhD}$, et al. reported on pilot data from a randomized trial of cardiopulmonary fitness for trauma-exposed Veterans who were otherwise healthy or had chronic pain and comorbid PTSD. In this context, the investigators demonstrated neurobiological correlates of pain threshold and tolerance during an analog task $30 \mathrm{~min}$ after exercise, providing preliminary evidence of a neurobiological mechanism for the hypothesized analgesic effects of exercise. Sarah L. Krein, PhD, RN, et al. examined the effects of a walking intervention for Veterans with chronic back pain, some of whom were concurrently being treated with long-term opioid therapy. They reported that those receiving long-term opioid therapy were not only willing to participate in the exercise program but that they actually improved their daily steps more than those not receiving opioid therapy, suggesting an incremental benefit of a structured walking program for Veterans receiving long-term opioid therapy. Together, these articles lend support for integrating exercise into a multimodal plan of care for Veterans with chronic pain.

Finally, this issue includes four articles that report on aspects of important VA practice and policy initiatives. Carol Elizabeth Fletcher, PhD, RN, et al. address the VA's efforts to promote core concepts of patientcentered care, especially the increased use of complementary and integrative health approaches. Their data provide confirmatory evidence of the perceived interest of Veterans in both inpatient and outpatient settings in using these approaches. A contribution by William C. Becker, MD, et al. reports on preliminary development of a novel approach to screening for harm, benefit, and misuse of opioid medications in the primary care setting. This work is entirely consistent with the VA's Opioid Safety Initiative designed to promote safe and effective long-term opioid therapy for a select group of Veterans who may benefit from this therapy. Brent A. Moore, PhD, et al. report on results of efforts at one VA facility and a non-VA Federally Qualified Health Center to implement the Stepped Care Model of Pain Management that was described by the IOM as a potential model of integrated, evidence-based, and patient-centered care. Finally, Evan P. Carey, MS, et al. report preliminary findings that document sub- stantial geographic dispersion of VA's Specialty Care Access Network-Extension of Community Healthcare Outcomes (SCAN-ECHO) initiative that uses video conferencing to promote case-based learning to enhance the competencies of primary care providers in their care of Veterans with pain.

\section{Robert D. Kerns, PhD; Alicia A. Heapy, PhD*}

VA Connecticut Healthcare System, West Haven, CT; Yale School of Medicine, New Haven, CT

*Email: alicia.heapy@va.gov

\section{REFERENCES}

1. Institute of Medicine. Relieving pain in America: A blueprint for transforming prevention, care, education, and research. Washington (DC): National Academies Press; 2011.

2. Haskell SG, Heapy A, Reid MC, Papas RK, Kerns RD. The prevalence and age-related characteristics of pain in a sample of women veterans receiving primary care. J Womens Health (Larchmt). 2006;15(7):862-69. [PMID:16999642]

http://dx.doi.org/10.1089/jwh.2006.15.862

3. Gironda RJ, Clark ME, Massengale JP, Walker RL. Pain among veterans of Operations Enduring Freedom and Iraqi Freedom. Pain Med. 2006;7(4):339-43.

[PMID:16533188]

http://dx.doi.org/10.1111/j.1526-4637.2006.00146.x

4. Lew HL, Otis JD, Tun C, Kerns RD, Clark ME, Cifu DX. Prevalence of chronic pain, posttraumatic stress disorder, and postconcussive symptoms in OEF/OIF veterans: Polytrauma clinical triad. J Rehabil Res Dev. 2009;46(6):697-702. [PMID:20104399] http://dx.doi.org/10.1682/JRRD.2009.01.0006

5. Lippe PM, Brock C, David J, Crossno R, Gitlow S. The First National Pain Medicine Summit-final summary report. Pain Med. 2010;11(10):1447-68. [PMID:21199301] http://dx.doi.org/10.1111/j.1526-4637.2010.00961.x

6. Gatchel RJ, Okifuji A. Evidence-based scientific data documenting the treatment and cost-effectiveness of comprehensive pain programs for chronic nonmalignant pain. J Pain. 2006;7(11):779-93. [PMID:17074616] http://dx.doi.org/10.1016/j.jpain.2006.08.005

7. Martell BA, O'Connor PG, Kerns RD, Becker WC, Morales $\mathrm{KH}$, Kosten TR, Fiellin DA. Systematic review: opioid treatment for chronic back pain: prevalence, efficacy, and association with addiction. Ann Intern Med. 2007;146(2):116-27. [PMID:17227935] 
http://dx.doi.org/10.7326/0003-4819-146-2-20070116000006

8. Kerns RD, Turk DC, Rudy TE. The West Haven-Yale Multidimensional Pain Inventory (WHYMPI). Pain. 1985;23(4): 345-56. [PMID:4088697] http://dx.doi.org/10.1016/0304-3959(85)90004-1

9. Kerns RD, Turk DC, Holzman AD, Rudy TE. Comparison of cognitive-behavioral and behavioral approaches to the outpatient treatment of chronic pain. Clin J Pain. 1985;1(4):195-203. http://dx.doi.org/10.1097/00002508-198501040-00003

10. Kerns RD, Booss J, Bryan M, Clark ME, Drake A, Gallagher RM, Green-Rashad B, Markham R, Rosenberg J, Turner A. Veterans Health Administration National Pain Management Strategy: Update and future directions. Am Pain Soc Bull. 2006;16:1-15.

11. Elnitsky C, Bryan M, Kerns RD. Veterans Health Administration's pain research portfolio and publications. J Rehabil Res Dev. 2007;44(2):xi-xviii.
[PMID:17551868]

http://dx.doi.org/10.1682/JRRD.2007.04.0056

This article and any supplementary material should be cited as follows:

Kerns RD, Heapy AA. Advances in pain management for Veterans: Current status of research and future directions. J Rehabil Res Dev. 2016;53(1):vii-x. http://dx.doi.org/10.1682/JRRD.2015.10.0196

ORCID: Robert D. Kerns, PhD: 0000-0001-76092771; Alicia A. Heapy, PhD: 0000-0003-1284-8263 